\title{
What Is the Next Step after Endoscopic Resection of Superficial Esophageal Squamous Cell Carcinoma?
}

\author{
Sang Gyun Kim \\ Department of Internal Medicine and Liver Research Institute, Seoul National University College of Medicine, Seoul, Korea
}

See "Treatment Strategy after Endoscopic Resection of Superficial Esophageal Squamous Cell Carcinoma: A Single Institution Experience" by Hyun Jik Lee, et al. on page 714-719, Vol. 9. No. 6, 2015

Although adenocarcinoma is the most common histology type in esophageal cancer in Western countries, squamous cell carcinoma is the most common type in Eastern countries. ${ }^{1}$ The risks of esophageal squamous cell carcinoma (ESCC) are known to be old age, smoking, alcohol intake, caustic injury, and history of head and neck cancer, among others. ${ }^{2}$ ESCC is usually evenly distributed between the middle and lower esophagus and can be located as multifocal lesions. ${ }^{3}$

Although surgical resection has been a mainstay of curative treatment modalities for ESCC, endoscopic resection (ER) has also been a curative treatment option for ESCC in indicated cases with minimal risk of lymph node metastasis (LNM). Although many studies have reported favorable clinical outcomes after ER for ESCC, additional treatment may be necessary for the cases with risk of $\mathrm{LNM}^{4,5}$ In ESCC, the deeper the tumor invasion, the higher the risk of LNM. Although the risk of LNM in ESCC confined to epithelial layer or lamina propria is minimal, LNM is found in $10 \%$ to $40 \%$ in ESCC that invades the muscularis mucosa or submucosa. ${ }^{6,7}$ Therefore, additional treatment may be necessary for patients with incomplete ER or tumor invasion into the muscularis mucosa or deeper layers irrespective of resection margin.

Surgical resection can be considered as an additional treatment option. However, it has a high morbidity and mortality rate, especially in old age. Moreover, surgical specimens often show no residual tumor or negative tumor involvement in LN dissection. If the patient has a comorbidity that can raise perioperative risk, it is difficult to consider surgical resection as an additional treatment option.

Radiotherapy (RT) can be considered as another additional treatment option. RT has the effect of reducing locoregional relapse from a residual tumor or LNM without significant morbidity. Additionally, chemotherapy or concurrent chemotherapy with RT can be an adjuvant treatment with less morbidity than surgical resection.

Although the risk of LNM increases with the depth of tumor invasion, all ESCC that invade the muscularis mucosa or deeper do not have LNM. Even for the cases with tumor invasion over the muscularis mucosa, adjuvant treatment can be an over-treatment and may increase severe morbidity rather than increasing the cure rate. Therefore, additional treatment should be cautiously considered by weighing the risk of LNM and the possibility of morbidity.

In this study, 54\% of the patients with ER for ESCC had tumor invasion into the muscularis mucosa or submucosa, and half of the patients received additional treatment. ${ }^{8}$ LNM was found in one-third of patients who underwent surgical resection. All the patients with ER alone or additional treatment showed an excellent prognosis during follow-up without recurrence of disease. There have been many debates regarding the patients for whom additional treatment is mandatory. Because all patients with tumor invasion into the muscularis or deeper do not have LNM, tailored therapy should be considered to reduce the risk of morbidity as well as the recurrence of disease. To demonstrate the effect of additional treatment, prospective randomized studies are needed.

\section{CONFLICTS OF INTEREST}

No potential conflict of interest relevant to this article was reported.

Correspondence to: Sang Gyun Kim

Department of Internal Medicine and Liver Research Institute, Seoul National University College of Medicine, 101 Daehak-ro, Jongno-gu, Seoul 03080, Korea

Tel: +82-2-740-8112, Fax: +82-2-743-6701, E-mail: harley@snu.ac.kr pISSN 1976-2283 eISSN 2005-1212 http://dx.doi.org/10.5009/gnl15109

(a) This is an Open Access article distributed under the terms of the Creative Commons Attribution Non-Commercial License (http://creativecommons.org/licenses/by-nc/4.0) which permits unrestricted non-commercial use, distribution, and reproduction in any medium, provided the original work is properly cited. 


\section{REFERENCES}

1. Enzinger PC, Mayer RJ. Esophageal cancer. N Engl J Med 2003; 349:2241-2252.

2. Brown LM, Hoover R, Silverman D, et al. Excess incidence of squamous cell esophageal cancer among US black men: role of social class and other risk factors. Am J Epidemiol 2001;153:114-122.

3. Daly JM, Fry WA, Little AG, et al. Esophageal cancer: results of an American College of Surgeons Patient Care Evaluation Study. J Am Coll Surg 2000;190:562-572.

4. Ishihara $\mathrm{R}$, Tanaka $\mathrm{H}$, lishi $\mathrm{H}$, et al. Long-term outcome of esophageal mucosal squamous cell carcinoma without lymphovascular involvement after endoscopic resection. Cancer 2008;112:21662172.

5. Joo DC, Kim GH, Park DY, Jhi JH, Song GA. Long-term outcome after endoscopic submucosal dissection in patients with superficial esophageal squamous cell carcinoma: a single-center study. Gut Liver 2014;8:612-618.

6. Eguchi T, Nakanishi Y, Shimoda T, et al. Histopathological criteria for additional treatment after endoscopic mucosal resection for esophageal cancer: analysis of 464 surgically resected cases. Mol Pathol 2006;19:475-480

7. Kim DU, Lee JH, Min BH, et al. Risk factors of lymph node metastasis in T1 esophageal squamous cell carcinoma. J Gastroenterol Hepatol 2008;23:619-625.

8. Lee HJ, Lee H, Park JC, Shin SK, Lee SK, Lee YC. Treatment strategy after endoscopic resection of superficial esophageal squamous cell carcinoma: a single institution experience. Gut Liver 2015;9:714-719. 